University of Wollongong

Research Online

Faculty of Science - Papers (Archive)

Faculty of Science, Medicine and Health

$1-1-2012$

\title{
The influence of prescribed fire on the extent of wildfire in savanna landscapes of western Arnhem Land, Australia
}

Owen F. Price

University of Wollongong, oprice@uow.edu.au

Jeremy Russell-Smith

Djwp Revel Pty Ltd

Felicity Watt

Bushfires NT

Follow this and additional works at: https://ro.uow.edu.au/scipapers

Part of the Life Sciences Commons, Physical Sciences and Mathematics Commons, and the Social and Behavioral Sciences Commons

\section{Recommended Citation}

Price, Owen F.; Russell-Smith, Jeremy; and Watt, Felicity: The influence of prescribed fire on the extent of wildfire in savanna landscapes of western Arnhem Land, Australia 2012, 297-305.

https://ro.uow.edu.au/scipapers/4739

Research Online is the open access institutional repository for the University of Wollongong. For further information contact the UOW Library: research-pubs@uow.edu.au 


\title{
The influence of prescribed fire on the extent of wildfire in savanna landscapes of western Arnhem Land, Australia
}

\author{
Abstract \\ Fire regimes in many north Australian savanna regions are today characterised by frequent wildfires \\ occurring in the latter part of the 7-month dry season. A fire management program instigated from 2005 \\ over $24000 \mathrm{~km} 2$ of biodiversity-rich Western Arnhem Land aims to reduce the area and severity of late \\ dry-season fires, and associated greenhouse gas emissions, through targeted early dry-season prescribed \\ burning. This study used fire history mapping derived mostly from Landsat imagery over the period \\ 1990-2009 and statistical modelling to quantify the mitigation of late dry-season wildfire through \\ prescribed burning. From 2005, there has been a reduction in mean annual total proportion burnt (from 38 \\ to $30 \%$ ), and particularly of late dry-season fires (from 29 to $12.5 \%$ ). The slope of the relationship between \\ the proportion of early-season prescribed fire and subsequent late dry-season wildfire was $\sim-1$. This \\ means that imposing prescribed early dry-season burning can substantially reduce late dry-season fire \\ area, by direct one-to-one replacement. There is some evidence that the spatially strategic program has \\ achieved even better mitigation than this. The observed reduction in late dry-season fire without \\ concomitant increase in overall area burnt has important ecological and greenhouse gas emissions \\ implications. This efficient mitigation of wildfire contrasts markedly with observations reported from \\ temperate fire-prone forested systems.
}

\section{Keywords}

extent, wildfire, savanna, landscapes, western, fire, arnhem, influence, land, australia, prescribed

\section{Disciplines}

Life Sciences | Physical Sciences and Mathematics | Social and Behavioral Sciences

\section{Publication Details}

Price, O. F., Russell-Smith, J. \& Watt, F. (2012). The influence of prescribed fire on the extent of wildfire in savanna landscapes of western Arnhem Land, Australia. International Journal of Wildland Fire, 21 (3), 297-305. 
The influence of prescribed fire on the extent of wildfire in savanna landscapes of western Arnhem Land, Australia

Running head: Prescribed vs wildfire in savannas

Owen Price ${ }^{1}$ Jeremy Russell-Smith ${ }^{2,3}$, Felicity Watt ${ }^{2,3}$

${ }^{1}$ Institute for Conservation Biology and Environmental Management, University of Wollongong, New South Wales 2522, Australia.

${ }^{2}$ Bushfires NT, PO Box 37346, Winnellie 0821, Northern Territory, Australia

${ }^{3}$ Tropical Savannas Management Cooperative Research Centre, Charles Darwin University, Darwin 0909, Northern Territory, Australia 


\section{Abstract}

Fire regimes in many north Australian savanna regions are today characterised by frequent wildfires occurring in the latter part of the seven-month dry season. A fire management program instigated from 2005 over $24,000 \mathrm{~km}^{2}$ of biodiverse-rich Western Arnhem Land aims to reduce the area and severity of late dry-season fires, and associated greenhouse gas emissions, through targeted early dry season prescribed burning. This study used fire history mapping derived mostly from Landsat imagery over the period 1990-2009, and statistical modelling, to quantify the mitigation of late dry season wildfire through prescribed burning. From 2005, there has been a reduction in mean annual total proportion burnt (from 38\% to 30\%), and particularly of late dry season fires (from $29 \%$ to $12.5 \%$ ). The slope of the relationship between the proportion of early season prescribed fire and subsequent late dry season wildfire was $\sim-1$. This means that imposing prescribed early dry season burning can substantially reduce late dry season fire area, by direct one-to-one replacement. There is some evidence that the spatially strategic program has achieved even better mitigation than this. The observed reduction in late dry season fire without concomitant increase in overall area burnt has important ecological and greenhouse gas emissions implications. This efficient mitigation of wildfire contrasts markedly with observations reported from temperate fire-prone forested systems.

Keywords: Leverage, wildfire, fire management, planned fire, unplanned fire, greenhouse gas emissions 


\section{Brief Summary}

Fire history mapping for 1990-2009 is used to quantify the mitigation of late dry season wildfire (LDS) through prescribed burning in Western Arnhem Land. Prescribed burning can substantially reduce LDS area, by direct one-to-one replacement. A management program operating since 2005 has successfully reduced LDS using prescribed fire. 


\section{Introduction}

Wildfires cause land managers problems in many parts of the world (Bradstock and Gill 2001; Fernandes 2008; Keeley and Fotheringham 2001). In most of these areas, the use of prescribed fires to reduce fuels is a key strategy for managing the size, severity and impact of wildfires (Baeza, De Luis et al. 2002; Cheney 1994; Collins, Kelly et al. 2007; Fernandes and Botelho 2003; Finney 2007; Gould, McCaw et al. 2007; Luke and McArthur 1977; McCarthy and Tolhurst 2004; Mitchell, Harmon et al. 2009). However, the effectiveness of prescribed fire has rarely been evaluated at practical management scales (Bradstock 2003; Fernandes and Botelho 2003; Finney 2007).

This knowledge gap has recently been addressed by exploring the relationship between the area recently burnt and the area subsequently burnt using historical fire mapping. Loehle (2004) introduced the term Leverage to be the reduction in area of subsequent fire resulting from the treatment of one unit area. It can be derived empirically as the absolute value of the slope of the relationship between annual area treated (x) and subsequent annual area of wildfire (y). Where Leverage $>1$, prescribed burning treatment leads to a reduction in the total area burnt (by prescribed and wildfires) but where Leverage $<1$, treatment increases the total area burnt. Price and Bradstock (2011) examined this relationship using 30 years of mapping in four sub-regions for eucalypt forest near Sydney, Australia. They found that Leverage was 0.33 ( 3 units of prescribed fire are required to reduce wildfire area by 1 unit). Boer et al. (2009) conducted a similar analysis using 50 years of mapping for a single region of eucalypt forest in Western Australia and found a negative exponential relationship with a Leverage of ca. 0.2 at contemporary levels of treatment. These two studies 
provide a quantitative estimate of return-for-effort from fire management in their respective regions.

These studies imply that a large treatment effort is required to substantially reduce the area of wildfire and that an increase in the total area burnt will result from treatment, because Leverage $<1$. There is no comparable information for other fire-prone biomes around the world. Such information is necessary to predict the effort required to alter wildfire regimes in any particular biome, and more generally to explore the biophysical drivers of Leverage among biomes. Several recent papers have proposed increasing prescribed burning treatment to reduce greenhouse gas emissions (Hurteau, Koch et al. 2008; Narayan, Fernandes et al. 2007). Leverage has a profound influence on whether such abatement could be achieved in any biome. If Leverage is considerably less than 1 (as it is in the two cases studied to date), then emissions abatement is doubtful (Bradstock and Williams 2009; Price and Bradstock 2011).

In Western Arnhem in the tropical savannas of northern Australia a greenhouse gas mitigation project based on fire management has been implemented successfully since 2005. The depopulation of indigenous land managers from across the northern savannas by the early- to mid- $20^{\text {th }}$ Century resulted in a marked shift in fire regime from one dominated by the extensive application of small early dry season fires, to one where most of the annual fire area is due to large, relatively intense wildfires in the late dry season (Bowman 1998; Russell-Smith, Yates et al. 2003). This has had negative consequences for biodiversity in general (Franklin 1999; Trainor and Woinarski 1994; Woinarski, Milne et al. 2001), and particularly for obligate seeding 
plant species (Bowman, Price et al. 2001; Bowman and Panton 1993; Liddle and Gibbons 2006; Russell-Smith, Ryan et al. 2001).

The WALFA (Western Arnhem Land Fire Abatement) project has many objectives, including addressing biodiversity concerns and re-empowering indigenous landholders. However, the funding for the project relies on an economic objective, which is to reduce greenhouse gas emissions by 100,000 tonnes p.a. (Whitehead, Purdon et al. 2008). While fire mapping has shown the overall area burnt per year has been reduced compared to a pre-management baseline (1995-2004), there is no empirical evidence about how much effort is required to achieve a certain outcome.

In this paper, we use a similar method to Price and Bradstock (2011) to investigate the relationship between prescribed fire and subsequent wildfire for the WALFA project area. The first objective was to improve the scientific foundation for the fire management program. A second objective is to compare Leverage in tropical savannas with temperate eucalypt forests. While our analysis assumes randomness in landscape patterning of fire over a twenty year assessment period, we address issues relating to strategic fire management (non-random effects) in the discussion.

\section{Method}

\section{Study area}

The Western Arnhem Land Fire Abatement (WALFA) study area covers approximately $24,000 \mathrm{~km}^{2}$ immediately to the east of Kakadu National Park (Figure 1). The north-west quarter of the region comprises a rugged sandstone plateau 
dissected by cliffs and gorges, but otherwise the region is characterised by undulating sandy plains. The central area, the Marrawal Plateau, forms the headwaters of several major watercourses, the largest of which are the East Alligator, Katherine, Mann and Liverpool Rivers. There are no permanent settlements in the region, with most of the population living in small townships outside the area (Bulman - population, 336; Maningrida, 492; and the mining town of Jabiru within Kakadu National Park, 1524: Australian Bureau of Statistics Census 2001). There are no sealed roads, and the few gravel roads are impassable during the wet season. The vegetation is a savanna woodland that varies in tree cover and species composition. Before the management program commenced, on average $38 \%$ of the study area burned each year. For more details about the vegetation and contemporary fire regime, see Edwards and RussellSmith (2009).

The climate is monsoonal and approximately $95 \%$ of the annual rainfall of $1300-1600$ mm falls during the wet season from November to April. As the dry season progresses, the predominantly grass fuels cure progressively. Two fire seasons are defined here: early dry season (EDS, up to July 31st) that are usually prescribed, and late dry season (LDS) that usually reflect unplanned fires (wildfires). LDS fires are typically much more extensive and intense than EDS fires (Edwards and Russell-Smith 2009; Russell-Smith and Edwards 2006). An area that is burnt by an EDS fire is unlikely to be burnt by a LDS fire. Fuel loads do not accumulate to pre-fire levels for 2-3 years (Russell-Smith, Murphy et al. 2009), so fire affected areas from the previous year may also inhibit fire spread.

[Figure 1 here] 
Data

The fire history of the study area, delineating EDS and LDS fires was mapped for the period 1990-2005 (Edwards and Russell-Smith 2009), and for 2006-2009 by one of the authors (FW), mostly from Landsat TM imagery using a well-established method, including validation (Edwards, Hauser et al. 2001; Price and Baker 2007). Up to 4 scenes were obtained for each year, with all fires occurring on each image mapped using a hybrid automatic and manual classification.

The study region was first divided into $20 \times 20 \mathrm{~km}$ blocks to increase the sample size. One potential consequence of this sub-sampling was that sample blocks might not be statistically independent of each other. This issue was addressed by choosing a block size larger than most individual fires (only $0.02 \%$ of fire polygons were larger, although these accounted for $47 \%$ of the area burnt), and by incorporating spatial autocorrelation in the analysis.

The mean LDS fire frequency over the 20 years (as in Figure 1) was calculated for each block. The percentage area of each block burnt in the EDS and LDS in each year was calculated. A range of environmental variables was also calculated for each block from available spatial data. Topographic variables including slope and rockiness are known to influence fire spread. Lacking a map of rockiness, we used mean elevation and slope, derived from a $30 \mathrm{~m}$ Digital Elevation Model (DEM). The dominant vegetation type was defined as one of two classes (Sandstone Heathlands and Lowland Eucalypt Woodland/Open Forests) to distinguish sandstone substrates from others, using the map developed by Edwards and Russell-Smith(2009). The density of 
drainage lines and distance to roads were calculated from digital layers from available 1:250 000 topographic maps (source: Geoscience Australia). Two biophysical Zones were distinguished demarked by the Mann River. The northern zone is dominated by rugged sandstone substrates and a dense drainage pattern whereas the southern zone is flatter with fewer drainage lines (Figure 1). Also, the Mann River is a potential fire barrier dividing the two zones. All of the variables used in the study are listed in Table 1.

\section{Analysis}

The area of LDS, EDS and total fire in pre- (1990-2004) and post- (2005-2009) management periods was compared for the entire study area (one value per year) and split into the two Zones (two values per year) using generalised linear modelling. The pattern of spatial autocorrelation in the overall frequency of LDS fire (number of fires experienced) was investigated by two methods. We examined the semi-variogram for 1000 points selected randomly, but with a minimum separation of $1 \mathrm{~km}$. We also calculated Moran's I for the mean values for three sets of data: all 57 blocks; the 28 blocks that only touch on the diagonals; and the 14 blocks that do not touch at all.

The regional drivers of spatial variation of LDS fire frequency were investigated by block in relation to the following environmental variables: the dominant vegetation type, mean elevation, mean slope, drainage density, and mean distance to the nearest road. This analysis was conducted as a Generalised Linear Model. To account for spatial autocorrelation, we added a Spatially-Lagged Response Variable (Haining 2003; Penman, Binns et al. 2008) to the model. This was the mean LDS fire 
frequency in the neighbouring blocks (mean of eight values for those blocks not on an edge). Also, the analysis was repeated using only the 14 non-touching blocks.

To investigate the relationship between annual EDS and LDS fire, the data for 57 blocks for each year were analysed using generalised linear mixed modelling. Since the data are repeated measures for the same blocks, they may not be independent. Mixed modelling differs from generalised linear modelling in that it can account for repeated measured by including a random variable in the model (in this case block). The dependent variable was LDS fire, and the primary independent variable was EDS fire. In the block analysis with the larger sample size, it was possible also to investigate the residual influence of fires from the previous year. Moreover, since this study was investigating the effect of EDS fires on LDS fires, the fires from the previous year were divided into prescribed and wildfires (Last EDS and Last LDS). To investigate whether different vegetation types exhibit different EDS-LDS relationships, we included the dominant vegetation type and its interaction with EDS fire. Similarly, since the management program instigated since 2005 was designed to address previous fire regime patterns we included the term Period (pre- or postWALFA management) and its interaction with EDS fire. All combinations of these five variables were fitted, and the best combination was selected using AIC. The goodness of fit of this model was assessed using a pseudo- $r^{2}$ statistic applicable to mixed models (Magee 1990). Any supported alternative models were also noted (those with $\triangle \mathrm{AIC}<2)$ (Burnham and Anderson 2002). To investigate whether the EDS vs LDS relationship was non-linear, we also included three variable combinations: adding $\mathrm{EDS}^{2}$; substituting EDS with $\mathrm{EDS}^{2}$; and substituting EDS with $\log (\mathrm{EDS})$. The total sample size for this analysis was 57 blocks $\mathrm{x} 19$ years $=1083$ 
(1990 could not be used as no EDS or LDS values for the previous year could be calculated).

To test whether the slope of the line was influenced by the large number of cases where no EDS fire was present, the best model above was re-fitted to data without zero cases $(n=819)$. To test whether spatial autocorrelation affected the results, we added a Spatially Lagged Response Variable, which in this case was the mean of LDS in the neighbouring cells.

To investigate whether the slope of the EDS vs LDS relationship is scale-sensitive, we repeated the analysis at three aggregated scales. First, groups of 4 blocks were combined into $13 \times 40 \mathrm{~km}$ squares $(n=247)$. Second, the data were split into the two biophysical Zones. Third, annual values for the entire study area were analysed $(n=19)$. The 'two zone' and 'whole of study area' analyses used Generalised Linear Modelling rather than Mixed Modelling. The potential for autocorrelation effects is much reduced in these larger scale analyses.

GIS analyses, the calculation of Moran's I and the semi-variograms were undertaken using Arcmap v 9.2. Statistical modelling was undertaken with R statistical software (R 2007).

\section{Results}

Over the twenty year study period, annual EDS fire area averaged $11.0 \%$ (range: $0.2 \%$ to $30.0 \%$ ) across the whole study area, LDS fire area averaged $24.7 \%$ (range: $4.6 \%$ to $62.2 \%$ ), and the total fire area averaged $35.7 \%$ (range: $10.3 \%$ to $67.9 \%$ : Figure 2 ). 
Values for 57 individual assessment blocks showed a much greater annual range: EDS 0 to $92 \%$; LDS 0 to $100 \%$. Fire activity changed after the WALFA management program commenced from 2005, with EDS fire area for the whole area increasing from $8.7 \%$ previously to $17.4 \%$, LDS fire area decreasing from $29.1 \%$ to $12.5 \%$, and total fire area decreasing more modestly from $37.7 \%$ to $29.9 \%$. The change in LDS fire and total fire was not significant for the annual data $(n=19, \mathrm{t}=2.012, p=0.060 ; \mathrm{t}$ $=0.953, \mathrm{p}=0.354$ for LDS and total fire respectively), but the change in EDS fire was $(\mathrm{t}=2.184, p=0.043)$. When the WALFA project area was considered as two biophysical zones, the change between Periods was significant for both EDS ( $n=38, \mathrm{t}$ $=2.929, p=0.005)$ and $\operatorname{LDS}(\mathrm{t}=2.462, p=0.018)$ fire area, but not for total fire $(\mathrm{t}=$ $1.007, \mathrm{p}=0.320)$

[Figure 2 here]

The LDS fire area values were weakly spatially auto-correlated (Moran's I $=0.143, \mathrm{Z}$ $=9.974, p<0.01)$. When only the 28 diagonally touching blocks were used, the correlation was less, but still significant $(I=0.061, Z=3.612, p<0.05)$. Likewise, when only the 14 non-touching blocks were used, the correlation was less again ( $\mathrm{I}=$ $0.021, Z=2.298, p<0.05)$. The semi-variogram suggests that autocorrelation is relatively strong at distances below $10 \mathrm{~km}$ but is absent at distances above $20 \mathrm{~km}$ (Figure 3). Therefore the choice of block size was appropriate.

[Figure 3 here]

The best model for regional drivers of LDS fire frequency revealed negative effects of Elevation, Slope and Drainage Density, and a positive effect of Distance to Roads (Table 2a). This model explained 55\% of variation. Two similar models were supported alternatives: one with the addition of Zone and one without Elevation. When neighbouring LDS fire area was added to the best model, it improved the 
overall fit $\left(\triangle \mathrm{AIC}=-5.19, \mathrm{r}^{2}=0.59\right)$, but weakened the effects of other explanatory variables (Table $2 b$ ). When the analysis was repeated with only 14 non-touching blocks, the best model contained Elevation and Slope with an $\mathrm{r}^{2}$ of 0.72 (Table 2c). There were nine alternative supported models which contained different combinations of three additional variables: Drainage Density, Distance to Roads and Vegetation. [Table 2 here]

In the mixed model analysis of 57 blocks x 19 years, the best model contained all three fire terms (EDS, Last EDS and Last LDS), plus EDS ${ }^{2}$, Dominant Vegetation, Period and Zone, and two interactions with EDS (Dominant Vegetation, Zone: Table 3a). The terms were all highly significant $(\mathrm{p}<0.001)$ except for the interactions, but the model explained only a relatively small proportion of the variation (pseudo- $\mathrm{r}^{2}=$ 0.22). The EDS effect had a primary slope of -0.987 , with a countering positive slope of 0.007 with $\mathrm{EDS}^{2}$. This means that the combined slope was -0.8 until EDS fire area reached $26 \%$ (Figure 4). The slopes for the effects of the previous year's fires were lower ( -0.35 for LDS, and -0.23 for EDS fires). Sandstone woodlands exhibited less LDS fire area and a shallower EDS slope than for Lowland woodlands, and the Southern Zone exhibited more LDS fire but a steeper slope with EDS burning. The time factor Period also had a significant effect, with more LDS fire in the premanagement phase. There were four alternative supported models, which all consisted of the same base variables but different combinations of interactions. The interaction between EDS and Period was in two of the supported alternative models. This means that there is possibly a small tendency for the slope of the relationship to be shallower (less negative) before the management program was implemented.

[Figure 4 here] 
Adding the mean LDS fire area of neighbouring cells markedly improved the model fit $\left(\right.$ pseudo- $\left.r^{2}=0.67\right)$, and although the other fire effects were still significant, their slopes were reduced (Table 3b). When zero fire cases were excluded in the best model formulation, the EDS slope was -1.18, with an $\operatorname{EDS}^{2}$ slope of +0.010 . The pseudo-r ${ }^{2}$ increased to 0.31 (Table 3c).

[Table 3 here]

When the blocks were grouped into 13 X $40 \mathrm{~km}$ blocks, the model was very similar, with a slope of -1.11 but with no square term (Table $4 a$ ), with a similar goodness of fit (pseudo- $\mathrm{r}^{2}=0.22$ ). There were two alternative supported models for this analysis: one without the EDS * Period interaction and one without also the Last EDS term. When annual data were separated into two Zones, the best model contained EDS (with a slope of -1.20), Last LDS fire and Zone (the Southern Zone had 18.9\% more LDS fire than the Northern Zone: Table $4 \mathrm{~b}$ ). This model had a pseudo-r ${ }^{2}$ of 0.33 . There were four alternative supported models for this analysis, which had additional effects of Last EDS fire and period. When the annual values for the whole study area were used, EDS and Last LDS fire were selected, with a slope of -1.16 for EDS fire (Table 4c). This model had a pseudo- $\mathrm{r}^{2}$ of 0.32 and the one alternative supported model had an additional effect of Last EDS.

[Table 4 here]

\section{Discussion}

The overall LDS fire frequency in the Western Arnhem Land study region is partially determined by environmental patterns: vegetation type, altitude, slope and drainage density. There are alternative explanations for these effects, but they are all consistent with affording some degree of fire protection: LDS fires are less frequent where many 
drainage lines form natural fire-breaks, and where the terrain is high and sloping, which is usually associated with rockiness and cliffs. Rockiness has been found to induce a degree of fire patchiness in LDS fires in this region (Price, Russell-Smith et al. 2003), while drainage line density has previously been found to affect fire frequency at random points within the same region (Price, Edwards et al. 2007). The southern Zone showed higher LDS fire area in all analyses. This region comprises mostly undulating to level terrain, with the lowest density of drainage lines.

Our data indicate that the WALFA fire management program has substantially reduced the incidence of LDS wildfires, including incursions from the south-east. The analysis confirms that the implementation of prescribed EDS burning was the main cause of the reduction. As expected, this study has demonstrated a strong relationship between EDS and LDS fire area. The slope of the relationship is difficult to estimate precisely because it varies slightly with scale, is affected by spatial autocorrelation, and is slightly non-linear. Bearing in mind that the 57 block $x 19$ year analysis is the most statistically powerful, it would appear that the slope is close to unity: one unit of LDS fire reduced for every unit of EDS fire applied. That is, Leverage is 1 . We use the Leverage calculated in the absence of the Spatially Lagged Response Variable. We interpret the effect of the Spatially Lagged Response Variable simply as providing evidence that the fire experienced within a block is to some extent influenced by events in surrounding blocks. This does not negate the Leverage value of 1 since this is the operational Leverage that will be achieved if treatments are applied across the whole WALFA region (i.e. where fires occur in neighbouring blocks). This conclusion is further reinforced by the Leverage values of 1 in the coarser scale analyses, where spatial autocorrelation was not present. 
However, the full situation is more complicated because there are additional effects of both EDS and LDS fires from the previous year, the magnitude of both being about one third of the effect in the current year. For the previous year, we can assume that the Last LDS fires are inhibited by the Last EDS fires in the same way as fires are in the current year (i.e. with a Leverage of 1). That is to say increasing EDS fire area will lead to exact replacement of LDS every year. Since the model states that Last LDS fires have a bigger inhibitory effect on LDS than do Last EDS fires (slope of $0.35 \mathrm{cf}-0.23$ ), it follows that increased application of EDS will lead to less inhibition from last years burning. Thus, over the long run, the replacement of LDS by EDS fire may be slightly less effective than the Leverage of 1 for EDS fire suggests.

The situation is even more complex due to the non-linearity in the relationship, although the non-linearity is so slight that there is very little implication for management. This result is similar to that found by (Price and Bradstock 2011) for the forests of the Sydney region in eastern Australia, where there was no evidence of nonlinearity and an empirical study in Jarrah forests of Western Australia (Boer, Sadler et al. 2009), which found a weak concave relationship. However, there was a marked concave relationship in a simulation study of Tasmanian forests (King, Cary et al. 2006). A linear relationship implies that there will be a certain level of treatment at which wildfires are eliminated. This can probably never occur in practice because treatment does not remove all sources of ignition, so a concave relationship is inevitable. 
The scale analysis identified a significant slope at all three spatial scales, and slopes were generally similar (varying from -0.99 to -1.2 ). This suggests that the inhibition of LDS fires by EDS burning is a general, scale-independent phenomenon in these regional savannas. These slopes are similar to that found by Gill et al. (2000) for annual fire areas in the neighbouring Kakadu National Park $(n=16$, slope $=-0.89)$. Kakadu is managed with similar objectives to the WALFA program. The statistical relationship suggests that it is theoretically possible to eliminate LDS fires by burning between $45 \%$ and $65 \%$ of the area in the EDS. However, it is probably unachievable in practice. This is illustrated by the six cases where EDS fire areas exceeded $60 \%$, and yet more than $10 \%$ was burnt by LDS fires. Logically, as long as there are unburnt areas and potential ignition sources (including from lightning at the very end of the dry season), LDS fires must always be a possibility.

These models captured only a small fraction of the variation in LDS fire area. This is partly because environmental drivers identified in the regional analysis, were not incorporated into mixed modelling analyses. However, fire ignitions are partially random events. Many cases in our sample contained no LDS fire, probably not because EDS fires had some influence on them, but because there was no LDS ignition that year. Also, since it used only the area burnt, our analysis did not take into account non-random spatial arrangements and configurations of fire affected patches, and particularly those associated with the prescribed EDS fire management program instigated from 2005. In this regard it is notable that in the five year period of operation of the WALFA fire management program, there has been a $20.6 \%$ reduction (from $37.7 \%$ to $29.9 \%$ ) in mean total fire area, with a significance level of $p=0.35$, but incorporating a substantial increase in the mean area of strategic EDS burning. 
Much of the prescribed burning program focuses on strategic burning of linear firebreaks associated with sinuous landscape features such watercourses, valley bottoms and slopes, and tracks. As demonstrated here, the fire management program has substantially decreased the area of LDS fire, more than would be expected by the 1:1 EDS-LDS relationship, and the total area burnt has also decreased. The two supported alternative models with an EDS.Period interaction give some weak evidence that Leverage may have increased as a result of the program. However, since only 5 of the 19 years studied here were post-management, it is probable that more time is needed to show the effect statistically. It is likely that the strategic spatial arrangement of the EDS areas has enhanced the return for effort above parity. Such an effect has been demonstrated in simulation studies (Finney 2001; King, Cary et al. 2006). However, there are other potential causes for the large reduction in LDS, including a reduction in LDS ignitions due to improved community awareness brought about by the WALFA program.

Does spatial autocorrelation inhibit the interpretation of these results? The evidence suggests not: the magnitude of the autocorrelation (Moran's I) was low; the semivariogram indicates that the correlation essentially disappears above $20 \mathrm{~km}$ separation; the relationships remained when a spatial autocorrelate was included in the models (albeit with reduced slope); and the relationships were robust when the analyses were repeated with only blocks separated by $40 \mathrm{~km}$.

What are the implications of this study for WALFA? We have shown that management via imposing prescribed EDS burning can substantially reduce LDS fire 
area, by direct one-to-one replacement. Moreover, EDS fires are known to be typically more patchy than LDS fires $(29.1 \%$ unburnt in EDS and $11.1 \%$ in LDS (Price, Russell-Smith et al. 2003; Russell-Smith, Murphy et al. 2009)), and to burn at lower intensity (Russell-Smith and Edwards 2006; Williams, Gill et al. 2003). Both these features have significant implications for conservation management (Woinarski, Williams et al. 2005; Yates, Edwards et al. 2008) and GHG emissions abatement (Cook and Meyer 2009; Russell-Smith, Murphy et al. 2009). Given lower fuel consumption rates achieved under EDS-dominated fire regimes, (Russell-Smith, Murphy et al. 2009) have estimated that EDS fires in this study area typically emit $48 \%$ of the Kyoto-accountable greenhouse gases $\left(\mathrm{CH}_{4}, \mathrm{~N}_{2} \mathrm{O}\right)$ per hectare burnt, compared with LDS fires. This calculation incorporates the finding that emission ratios of greenhouse gasses do not vary throughout the season in Australian savannas (Meyer and Cook 2010), even though they have been shown to increase as the dry season progresses in Zambian savanna grassland (Hoffa, Ward et al. 1999).

Could these results be generalised to other fire-prone biomes? In the sclerophyll forests of Sydney (south-eastern Australia) the slope of return for effort is much lower $($ Leverage $=0.33:($ Price and Bradstock 2011) $)$ while, in the Jarrah forests of Western Australia, it is lower still (Leverage $=0.25$ : $($ Boer, Sadler et al. 2009)). This is probably because these temperate forested landscapes are much less saturated by fire (mean area burnt annually $=5 \%$ ), so that there is less chance that a prescribed fire patch will be encountered a wildfire. On the other hand, the fact that fuels take several years to recover in these forests presumably enhances the inhibitory effect of prescribed fires. Based partly on the results of this study and those of Price and Bradstock (2011) and Boer et al. (2009), Bradstock and Williams (2009) concluded 
that emission abatement benefits are attainable in Australian savannas, but not in temperate Australian forests.

Savannas constitute the most fire-prone biome on earth (Dwyer, Pinnock et al. 2000), and Australian savannas are as fire-prone as those on other continents (Roy, Boschetti et al. 2008). Therefore, we consider that the magnitude of leverage demonstrated here is likely the upper limit of what can realistically be achieved at landscape scale- $\mathrm{a}$ conclusion at odds with assumptions made by certain other authors. For example, Narayan et al. (2007) claimed that an annual prescribed burning program of $5 \%$ of the area of European forests could result in a major reduction in the net area burnt, though they provided no evidence for this. Likewise, Hurteau et al. (2008) claimed that reducing fuels in US forests would reduce GHG emissions through reduced fire severity, though they did not account for the emissions from fuel reduction in areas that don't subsequently encounter a wildfire. Conversely, Mitchell et al. (2009) show that while fuel reduction treatments in west coast US forested ecosytems consistently reduced fire severity, fuel reduction also resulted in reduced mean stand C storage. By contrast, effecting major fire regime change in savanna systems through EDS prescribed burning can substantially enhance $\mathrm{C}$ accumulation in living biomass (Murphy, Russell-Smith et al. 2010; Murphy, Russell-Smith et al. 2009). In sum, fire management in savanna landscapes can achieve multiple biodiversity and carbon conservation benefits. 


\section{Acknowledgements}

We thank Andrew Edwards for providing the vegetation and fire mapping, and

Cameron Yates and Ross Bradstock for discussions about methodology and conclusions. This work was funded by Land and Water Australia, and the Tropical Savannas Cooperative Research Centre. 
Table 1: Variables used in the analysis

\begin{tabular}{|c|c|}
\hline Variable & Description \\
\hline \multicolumn{2}{|c|}{ Regional LDS Frequency Analysis } \\
\hline LFRQ & $\begin{array}{l}\text { Dependent variable: Late dry season Fire Frequency (mean for } 20 \times 20 \\
\text { km block over } 19 \text { years) }\end{array}$ \\
\hline Neighbour LFRQ & Mean LFRQ for 8 neighbouring $20 \times 20 \mathrm{~km}$ blocks \\
\hline Elevation & Elevation in m (from 30 m DEM) \\
\hline Slope & Slope in degrees (from 30 m DEM) \\
\hline Distance to Roads & $\begin{array}{l}\text { Distance to nearest road in m (from 1:250,000 topographic map } \\
\text { supplemented with GPS tracks for unmapped tracks (authors data)) }\end{array}$ \\
\hline Drainage Density & $\begin{array}{l}\text { Area weighted length of drainage lines in sample area (from 1:250 } 000 \\
\text { topographic map) }\end{array}$ \\
\hline \multicolumn{2}{|l|}{ Annual Analysis } \\
\hline LDS & $\begin{array}{l}\text { Dependent variable: Late Dry Season fire: \% of block area burnt in one } \\
\text { year }\end{array}$ \\
\hline Neighb_LDS & Mean LDS for 8 neighbouring $20 \times 20 \mathrm{~km}$ blocks \\
\hline EDS & Early Dry Season fire: \% of sample area burnt in one year \\
\hline Last LDS & Late Dry Season fire from previous year \\
\hline Last EDS & Early Dry Season fire from previous year \\
\hline Zone & North or South of line demarcated by the Mann River \\
\hline Period & Time period: Pre- or Post- WALFA project (2005) \\
\hline Dominant Veg. & Sandstone Heathland or Lowland Eucalypt Woodland/Open Forest \\
\hline
\end{tabular}


Table 2: GLM results for the regional drivers of LDS frequency a) Best model (AIC $\left.\left.=172.85, r^{2}=0.542\right) . b\right)$ Incorporating Neighbour LFRQ. AIC $=$ $\left.167.66, \mathrm{r}^{2}=0.593\right)$. No supported alternative models. c) With only 14 non-touching blocks. (AIC $\left.=36.289, \mathrm{r}^{2}=0.718, \mathrm{df}=3\right) .9$ supported alternative models (not shown, but variables include Drainage Density, Distance to Roads and Vegetation, though none are statistically significant).

a)

\begin{tabular}{lrrrr}
\hline Variable & Estimate & Std. Error & t-value & $p$-value \\
\hline (Intercept) & 7.946 & 0.989 & 8.038 & 0.000 \\
Elevation & -0.003 & 0.002 & -1.564 & 0.124 \\
Slope & -0.822 & 0.202 & -4.070 & 0.000 \\
Distance to Roads & $4.21 \mathrm{e}^{-5}$ & 0.000 & 2.940 & 0.005 \\
Drainage Density & -2.441 & 1.264 & -1.931 & 0.059 \\
\hline
\end{tabular}

b)

\begin{tabular}{lrrrr}
\hline Variable & Estimate & Std. Error & t-value & $p$-value \\
\hline (Intercept) & 3.079 & 2.151 & 1.432 & 0.158 \\
Elevation & -0.002 & 0.002 & -0.764 & 0.448 \\
Slope & -0.455 & 0.241 & -1.887 & 0.065 \\
Distance to Roads & 0.000 & 0.000 & 2.272 & 0.027 \\
Drainage Density & -1.055 & 1.324 & -0.797 & 0.429 \\
Neighbour LFRQ & 0.639 & 0.254 & 2.517 & 0.015 \\
\hline
\end{tabular}


c)

\begin{tabular}{lrrrr}
\hline Variable & Estimate & Std. Error & $t$-value & $p$-value \\
\hline (Intercept) & 8.501 & 1.179 & 7.213 & 0.000 \\
Elevation & -0.005 & 0.002 & -1.791 & 0.101 \\
Slope & -1.202 & 0.241 & 4.978 & 0.000 \\
\hline
\end{tabular}


Table 3: Model estimates for the annual analysis (19 years x 57 blocks). In each case, the best model from the model selection process is shown. a) Without a spatial lag variable, $\mathrm{AIC}=10168.36$, pseudo- $\left.^{2}=0.217 . \mathrm{b}\right)$ With spatial lag variable (Neighbour $\mathrm{LDS}), \mathrm{AIC}=9233.858, \Delta \mathrm{AIC}=-936($ difference in AIC between models a and $\mathrm{b})$, pseudo-r ${ }^{2}=0.671$ c) As a) but with zero EDS samples removed, $n=834$, AIC $=$ 7761.552, pseudo- $\mathrm{r}^{2}=0.309$. An $*$ indicates an interaction term.

a)

\begin{tabular}{lrrrr}
\hline & Estimate & Std. Error & t-value & $p$-value \\
\hline (Intercept) & 37.454 & 3.478 & 10.768 & 0.000 \\
Zone: South & 11.907 & 3.159 & 3.769 & 0.000 \\
EDS & -0.987 & 0.164 & -5.999 & 0.000 \\
Sandstone Veg. & -11.724 & 3.229 & -3.631 & 0.001 \\
EDS & & & & \\
Last EDS & 0.007 & 0.003 & 2.912 & 0.004 \\
Last LDS & -0.233 & 0.056 & -4.155 & 0.000 \\
Period: Pre & -0.350 & 0.030 & -11.701 & 0.000 \\
EDS*Zone: South & 8.197 & 2.022 & 4.054 & 0.000 \\
EDS*Sandstone Veg. & -0.217 & 0.112 & -1.935 & 0.053 \\
& 0.218 & 0.125 & 1.745 & 0.081 \\
\hline
\end{tabular}


b)

\begin{tabular}{|c|c|c|c|c|}
\hline & Estimate & Std. Error & $t$-value & $p$-value \\
\hline (Intercept) & 11.428 & 2.210 & 5.170 & 0.000 \\
\hline Zone: South & 3.498 & 1.821 & 1.921 & 0.060 \\
\hline EDS & -0.412 & 0.107 & -3.846 & 0.000 \\
\hline Sandstone Veg. & -5.620 & 1.844 & -3.048 & 0.004 \\
\hline $\mathrm{EDS}^{2}$ & 0.002 & 0.002 & 1.069 & 0.286 \\
\hline Last EDS & -0.062 & 0.037 & -1.692 & 0.091 \\
\hline Last LDS & -0.112 & 0.020 & -5.536 & 0.000 \\
\hline Period: Pre & -0.702 & 1.341 & -0.524 & 0.601 \\
\hline Neighb_LDS & 0.926 & 0.024 & 38.494 & 0.000 \\
\hline EDS*Zone: South & -0.013 & 0.073 & -0.179 & 0.858 \\
\hline EDS*Sandstone Veg. & 0.131 & 0.081 & 1.610 & 0.108 \\
\hline
\end{tabular}

c)

\begin{tabular}{lrrrr}
\hline & Estimate & Std. Error & t-value & $p$-value \\
\hline (Intercept) & 40.960 & 3.672 & 11.156 & 0.000 \\
Zone: South & 13.681 & 3.441 & 3.976 & 0.000 \\
EDS & -1.181 & 0.170 & -6.941 & 0.000 \\
Sandstone Veg. & -8.557 & 3.547 & -2.412 & 0.019 \\
EDS $^{2}$ & 0.010 & 0.003 & 3.641 & 0.000 \\
Last EDS & -0.206 & 0.062 & -3.332 & 0.001 \\
Last LDS & -0.356 & 0.034 & -10.361 & 0.000 \\
Period: Pre & 13.006 & 2.125 & 6.121 & 0.000 \\
EDS*Zone: South & -0.273 & 0.122 & -2.231 & 0.026 \\
EDS*Sandstone Veg. & 0.090 & 0.129 & 0.699 & 0.485 \\
\hline
\end{tabular}


Table 4. Models estimates for sub-sets and sub-groups (best models only).

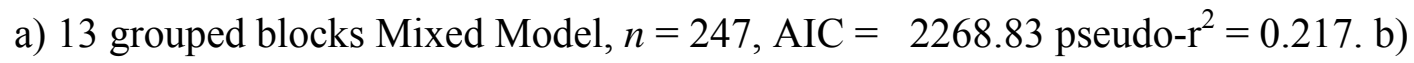

Two Zones GLM, $n=38, \mathrm{AIC}=328.09$, pseudo- $^{2}=0.326$. c) Whole study area

GLM, $n=19$, AIC $=161.28, \mathrm{r}^{2}=0.323$.

a)

\begin{tabular}{lrrrr}
\hline & Estimate & Std. Error & $t$-value & $p$-value \\
\hline (Intercept) & 46.898 & 6.929 & 6.768 & 0.000 \\
EDS & -1.109 & 0.289 & -3.844 & 0.000 \\
Last EDS & -0.179 & 0.133 & -1.347 & 0.179 \\
Last LDS & -0.389 & 0.063 & -6.197 & 0.000 \\
Sandstone Veg. & -13.044 & 5.693 & -2.291 & 0.043 \\
Period: Pre & 2.533 & 5.644 & 0.449 & 0.654 \\
EDS*Period: Pre & 0.562 & 0.302 & 1.861 & 0.064 \\
\hline
\end{tabular}

b)

\begin{tabular}{lrrrr}
\hline & Estimate & Std. Error & t-value & $p$-value \\
\hline (Intercept) & 43.519 & 7.087 & 6.141 & 0.000 \\
EDS & -1.200 & 0.339 & -3.538 & 0.001 \\
Last LDS & -0.481 & 0.169 & -2.841 & 0.008 \\
Zone: South & 18.888 & 6.161 & 3.066 & 0.004 \\
\hline
\end{tabular}

c)

\begin{tabular}{lrrrr}
\hline & Estimate & Std. Error & $t$-value & $p$-value \\
\hline (Intercept) & 48.783 & 9.603 & 5.080 & 0.000 \\
EDS & -1.161 & 0.453 & -2.562 & 0.021 \\
Last LDS & -0.450 & 0.229 & -1.964 & 0.067 \\
\hline
\end{tabular}




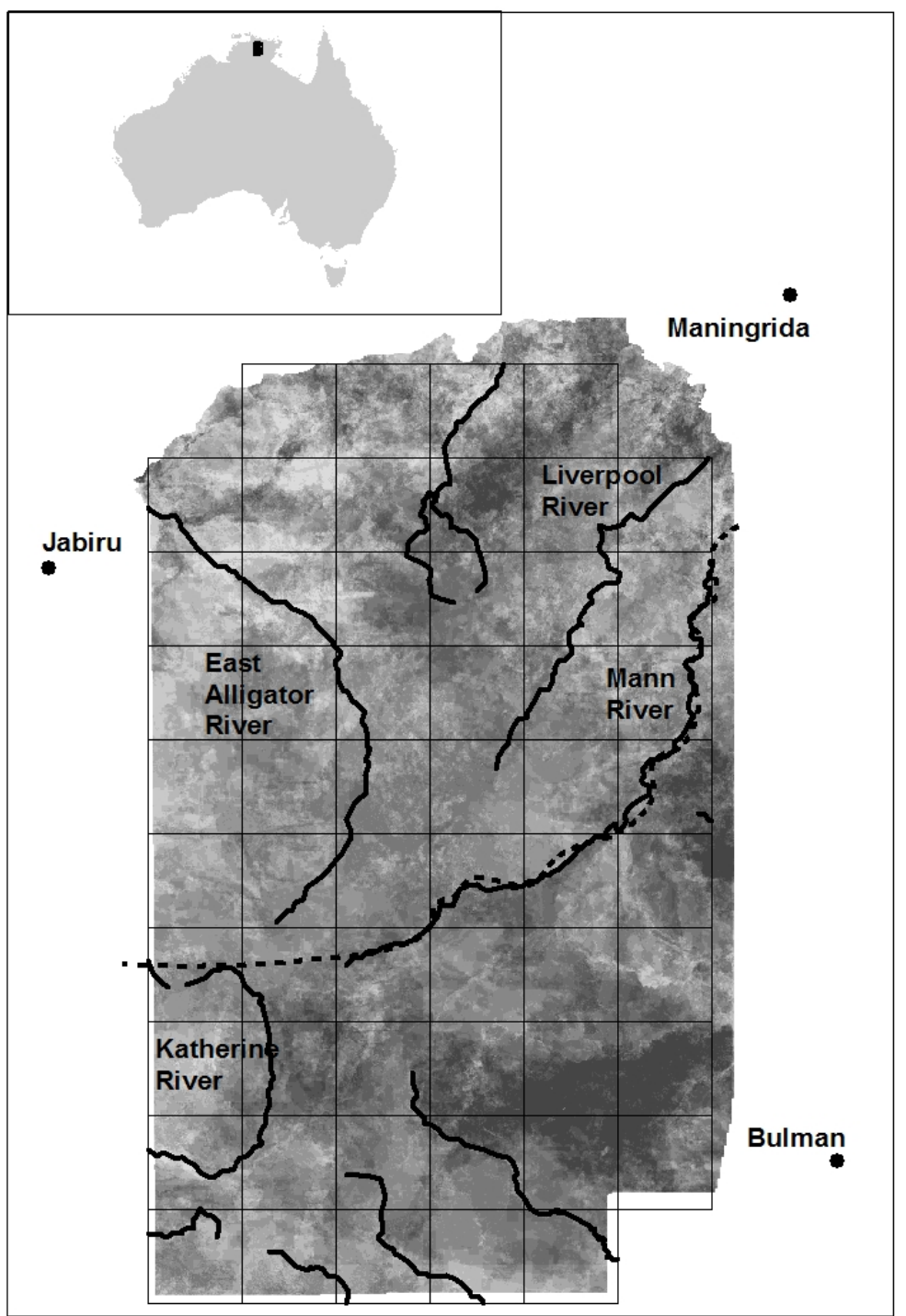

Figure 1: West Arnhem Land showing larger settlements, the 5720 x $20 \mathrm{~km}$ blocks, and the frequency of late dry season fires from 1991-2009 (range 0 (white) - 15 (dark grey)). The dashed line is the boundary to the two zones. 


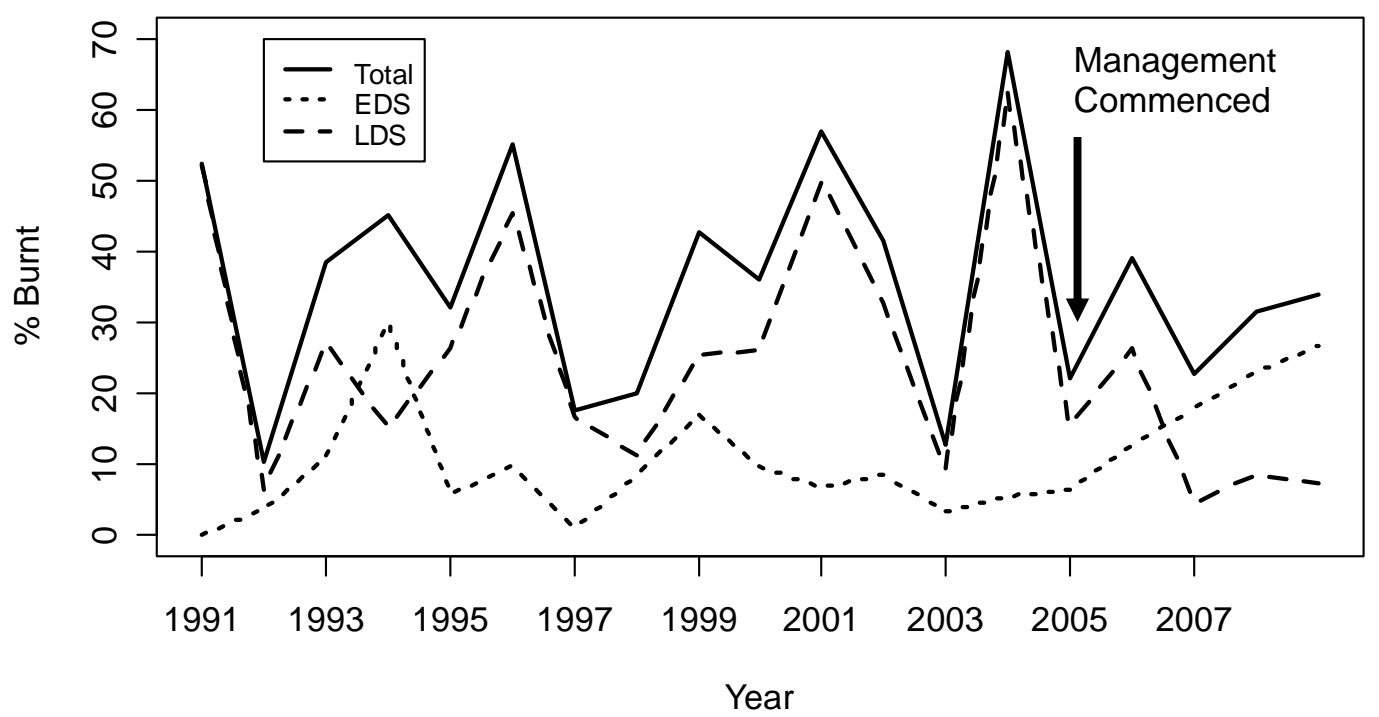

Figure 2: Time trace showing the percentage of the study area burnt each year by EDS (early dry season) and LDS (late dry season) fires each year. 


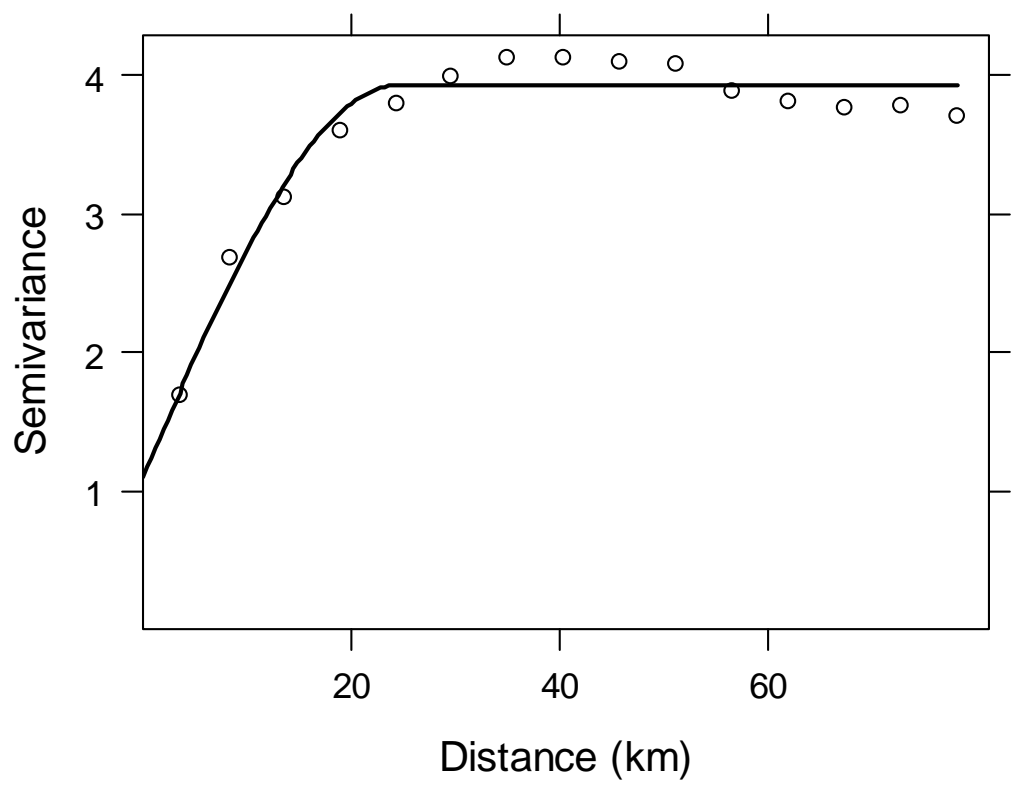

Figure 3: Semi-variogram for mean Late Dry Season Fire frequency $(n=57)$. Semivariance is a measure of the dis-similarity of points, and the variogram shows how this increases with separation between points. 


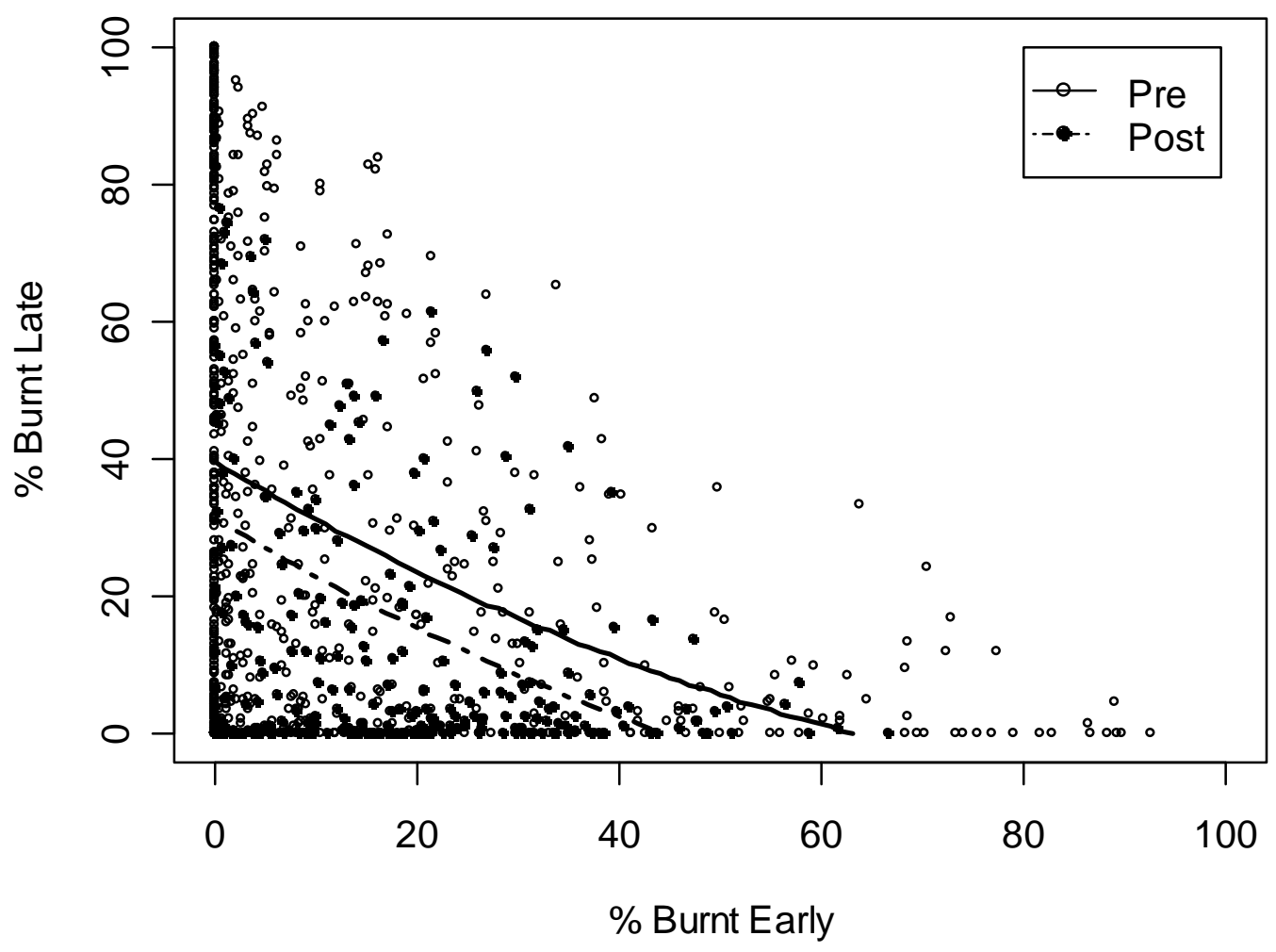

Figure 4: The relationship between early and late dry season burning, showing the raw data points and the best fit model for Pre- and Post- management periods (open and closed circles respectively). 


\section{References}

Baeza MJ, De Luis M, Raventos J, Escarre A (2002) Factors influencing fire behaviour in shrublands of different stand ages and the implications for using prescribed burning to reduce wildfire risk. Journal of Environmental Management 65, 199-208.

Boer MM, Sadler RJ, Wittkuhn R, McCaw L, Grierson PF (2009) Long-term impacts of prescribed burning on regional extent and incidence of wildfires - evidence from fifty years of active fire management in SW Australian forests. Forest Ecology and Management 259, 132-142.

Bowman DJMS, Price O, Whitehead PJ, Walsh A (2001) The 'wilderness effect' and the decline of Callitris intratropica in Western Arnhem Land, northern Australia. Aust. J. Botany 49, 665-672.

Bowman DMJS (1998) Tansley Review No. 101: The impact of Aboriginal landscape burning on the Australian biota. New Phytologist 140, 385-410.

Bowman DMJS, Panton WJ (1993) Decline of Callitris intratropica R.T. Baker and H.G. Smith in the Northern Territory: Implications for pre- and post- European colonization fire regimes. Journal of Biogeogography 20, 373-381.

Bradstock R (2003) Protection of people and property: toward and integrated risk management model. In 'Australia Burning: fire ecology, policy and management issues'. (Ed. DLaSD G. Cary) pp. 119-123. (CSIRO: Collingwood)

Bradstock R, Williams RJ (2009) How might management mitigate emissions from fires? New Phytologist 183, 931-934.

Bradstock RA, Gill AM (2001) Living with fire and biodiversity at the urban edge: in search of a sustainable solution to the human protection problem in southern Australia. Journal of Mediterranean Ecology 2, 179-195. 
Burnham KP, Anderson DR (2002) 'Model selection and multimodel inference: A practical information-theoretic approach.' (Springer-Verlag: New York:)

Cheney P (1994) The effectiveness of fuel reduction burning for fire management. In 'Fire and biodiversity: the effects and effectiveness of fire management'. Footscray pp. 9-16. (Biodiversity Unit, Department of Environment, Sport and Territories)

Collins BM, Kelly M, van Wagtendonk JW, Stephens SL (2007) Spatial patterns of large natural fires in Sierra Nevada wilderness areas. Landscape Ecology 22, $545-557$.

Cook G, Meyer C (2009) Fire, fuels and greenhouse gases. In 'In Culture, ecology and economy of savanna fire management in northern Australia: rekindling the Wurrk tradition'. (Eds J Russell-Smith, P Whitehead and P Cooke) pp. 313-327. (CSIRO Publications: Melbourne)

Dwyer E, Pinnock S, Gregoire JM, Pereira JMC (2000) Global spatial and temporal distribution of vegetation fire as determined from satellite observations. International Journal of Remote Sensing 21, 1289-1302.

Edwards A, Hauser P, Anderson M, McCartney J, Armstrong M, Thackway R, Allan G, Hempel C, Russell-Smith J (2001) A tale of two parks: contemporary fire regimes of Litchfield and Nitmiluk National Parks, monsoonal northern Australia. International Journal of Wildland Fire 10, 79-89.

Edwards AC, Russell-Smith J (2009) Ecological thresholds and the status of firesensitive vegetation in western Arnhem Land, northern Australia: implications for management. International Journal of Wildland Fire 18, 127-146.

Fernandes PAM (2008) Forest fires in Galicia (Spain): The outcome of unbalanced fire management. Journal of Forest Economics 14, 155-157. 
Fernandes PM, Botelho HS (2003) A review of prescribed burning effectiveness in fire hazard reduction. International Journal of Wildland Fire 12, 117-128.

Finney MA (2001) Design of regular landscape fuel treatments for modifying fire growth and behaviour. Forest Science 47, 219-228.

Finney MA (2007) A computational method for optimising fuel treatment locations. International Journal of Wildland Fire 16, 702-711.

Franklin DC (1999) Evidence of disarray in granivorous bird assemblages in the savannas of northern Australia, a region of sparse human settlement. Biological Conservation 90, 53-68.

Gill AM, Ryan PG, Moore PHR, Gibson M (2000) Fire regimes of World Heritage Kakadu National Park, Australia. Austral Ecology 25, 616-625.

Gould JS, McCaw WL, Cheney NP, Ellis PF, Knight IK, Sullivan AL (2007) 'Project Vesta - fire in dry eucalypt forest: fuel structure, fuel dynamics and fire behaviour.' Ensis-CSIRO and Department of Environment and Conservation, Canberra.

Haining R (2003) 'Spatial Data Analysis.' (Cambridge University Press: Cambridge)

Hoffa E, Ward D, Hao W, Susott R, Wakimoto R (1999) Seasonality of carbon emissions from biomass burning in a Zambian savanna. Journal of Geophysical Research 104, 13841-13853.

Hurteau MD, Koch GW, A Hungate BA (2008) Carbon protection and fire risk reduction: toward a full accounting of forest carbon offsets. Frontiers in Ecology and Environment 6, 493-398.

Keeley JE, Fotheringham CJ (2001) Historic fire regime in Southern California shrublands. Conservation Biology 15, 1536-1548. 
King KJ, Cary GJ, Bradstock RA, Chapman J, Pyrke A, Marsden-Smedley JB (2006) Simulation of prescribed burning strategies in south-west Tasmania, Australia: effects on unplanned fires, fire regimes, and ecological management values. International Journal of Wildland Fire 15, 527-540.

Liddle DT, Gibbons A (2006) 'National recovery plan for Boronia quadrilata and Boronia viridiflora in the Northern Territory of Australia. Northern Territory.' Department of Natural Resources, Environment and the Arts, Darwin.

Loehle C (2004) Applying landscape principles to fire hazard reduction. Forest Ecology and Management 198, 261-267.

Luke R, H., McArthur AG (1977) 'Bushfire in Australia.' (Australian Government Publishing Service: Canberra)

Magee L (1990) R2 Measures Based on Wald and Likelihood Ratio Joint Significance Tests. American Statistician 44, 250-253.

McCarthy GJ, Tolhurst KG (2004) Effectiveness of broad scale fuel reduction burning in Victorian parks and forests. In 'Bushfire 2004: Earth Wind and Fire - fusing the elements'. Adelaide. (Department of Environment and Heritage)

Meyer CP, Cook G (2010) 'Seasonality of emission factors from savanna burning.' CSIRO, Melbourne.

Mitchell SR, Harmon ME, O'Connell KEB (2009) Forest fuel reduction alters fire severity and long-term carbon storage in three Pacific Northwest ecosystems. Ecological Applications 19, 643-655.

Murphy B, Russell-Smith J, Prior L (2010) Frequent fires reduce tree growth in north Australian savannas: implications for tree demography and carbon sequestration. Global Change Biology 16, 331-343. 
Murphy B, Russell-Smith J, Watt F, Cook G (2009) Fire management and woody biomass carbon stocks in mesic savannas. In 'In Culture, ecology and economy of savanna fire management in northern Australia: rekindling the Wurrk tradition'. (Eds J Russell-Smith, P Whitehead and P Cooke) pp. 361-394. (CSIRO Publications: Melbourne)

Narayan C, Fernandes PM, van Brusselen J, Schuck A (2007) Potential for CO2 emissions mitigation in Europe through prescribed burning in the context of the Kyoto Protocol. Forest Ecology and Management 251, 164-173.

Penman TD, Binns DL, Shiels RJ, Allen RM, Kavanagh RP (2008) Changes in understorey plant species richness following logging and prescribed burning in shrubby dry sclerophyll forests of south-eastern Australia. Austral Ecology 33, 197-210.

Price O, Baker B (2007) Fire regimes and their correlates in the Darwin region of northern Australia. Pacific Conservation Biology 13, 177-188.

Price O, Russell-Smith J, Edwards A (2003) Fine-scale patchiness of different fire intensities in sandstone heath vegetation in northern Australia. International Journal of Wildland Fire 12, 227-236.

Price OF, Bradstock R (2011) The influence of weather and fuel management on the annual extent of unplanned fires in the Sydney region of Australia. International Journal of Wildland Fire 20, 142-151.

Price OF, Edwards AC, Russell-Smith J (2007) Efficacy of permanent firebreaks and aerial prescribed burning in western Arnhem Land, NorthernTerritory, Australia. International Journal of Wildland Fire 16, 295-303.

R CDT (2007) A Language and Environment for Statistical Computing In. (R Foundation for Statistical Computing: Vienna, Austria) 
Roy DP, Boschetti L, Justice CO, Ju J (2008) The collection 5 MODIS burned area product - Global evaluation by comparison with the MODIS active fire product. Remote Sensing of Environment 112, 3690-3707.

Russell-Smith J, Edwards AC (2006) Seasonality and fire severity in savanna landscapes of monsoonal northern Australia. International Journal of Wildland Fire 15, 541-550.

Russell-Smith J, Murphy BP, Meyer CP, Cook GD, Maier S, Edwards AC, Schatz J, Brocklehurst P (2009) Improving estimates of savanna burning emissions for greenhouse accounting in northern Australia: limitations, challenges, applications. International Journal of Wildland Fire 18, 1-18.

Russell-Smith J, Ryan PG, Cheal D (2001) Fire regimes and the conservation of sandstone heath in monsoonal northern Australia: frequency, interval, patchiness. Biological Conservation 104, 91-106.

Russell-Smith J, Yates C, Edwards A, Allan GE, Cook GD, Cooke P, Craig R, Heath B, Smith R (2003) Contemporary fire regimes of northern Australia, 19972001: change since Aboriginal occupancy, challenges for sustainable management. International Journal of Wildland Fire 12, 283-297.

Trainor CR, Woinarski JCZ (1994) Responses of lizards to three experimental fires in the savanna forests of Kakadu National Park. Wildlife Research 21, 131-148.

Whitehead P, Purdon P, Russell-Smith J, Cooke P, Sutton S (2008) The management of climate change through prescribed savanna burning: emerging contributions of indigenous people in northern Australia. Public Administration and Development 28, 374-385. 
Williams R, Gill A, Moore P (2003) Fire behaviour. In 'Fire in Tropical Savannas: The Kapalga Experiment '. (Eds A Andersen, G Cook and R Williams) pp. 3346. (Springer-Verlag: New York)

Woinarski JCZ, Milne DJ, Wanganeen G (2001) Changes in mammal populations in relatively intact landscapes of Kakadu National Park, Northern Territory, Australia. Austral Ecology 26, 360-370.

Woinarski JCZ, Williams RJ, Price OF, Rankmore B (2005) Landscapes without boundaries: measuring quality of wildlife habitat in northern Australia. Wildlife Research 32, 377-388.

Yates CP, Edwards AC, Russell-Smith J (2008) Big fires and their ecological impacts in Australian savannas: size and frequency matters. International Journal of Wildland Fire 17, 768-781. 